03

\title{
Экспериментальное наблюдение явления перезамыкания прецессирующего вихревого жгута в турбине радиально-осевого типа
}

\author{
(C) Д.В. Платонов ${ }^{1,2}$, А.В. Минаков ${ }^{1,2, \text { ฯ Д.А. Дектерев }}{ }^{1,2}$, \\ А.В. Масленникова ${ }^{3}$, П.А. Куйбин ${ }^{2}$ \\ ${ }^{1}$ Сибирский федеральный университет, Красноярск \\ ${ }^{2}$ Институт теплофизики СО РАН, Новосибирск \\ ${ }^{3}$ Саяно-Шушенский фрилиал „Сибирского фредерального университета“, \\ Черемушки \\ ฯ E-mail: tov-andrey@yandex.ru
}

Поступило в Редакцию 27 марта 2017 г.

Представлены результаты экспериментальных исследований явления перезамыкания вихревого жгута в проточном тракте радиально-осевой гидротурбины. Исследования проведены на среднемасштабном гидродинамическом стенде с конструкцией, максимально приближенной к реальным гидроагрегатам. С помощью высокоскоростной сьемки в режиме с нагрузкой $75 \%$ в диффузоре отсасывающей трубы зафиксировано перезамыкание прецессирующего вихревого жгута с отрывом вихревых колец. Экспериментально установлены апериодические всплески давления, связанные с перезамыканием вихря и образованием вихревых колец.

DOI: 10.21883/PJTF.2017.21.45159.16794

Одна из причин повышенного уровня пульсаций давления и вибраций в гидротурбинах высоконапорных ГЭС - явление прецессирующего вихревого ядра. Прецессия вихревого жгута, образующегося за рабочим колесом гидротурбины в режимах частичной или форсированной нагрузки гидроагрегата, является основным механизмом генерации низкочастотных пульсаций потока, когда поток после прохождения через гидротурбину имеет достаточно большую остаточную закрутку [1-6]. Анализ экспериментальных и расчетных данных показывает [2-4], что максимальные пульсации давления наблюдаются в режимах частичной нагрузки на гидроагрегат (40-50\% от номинальной 


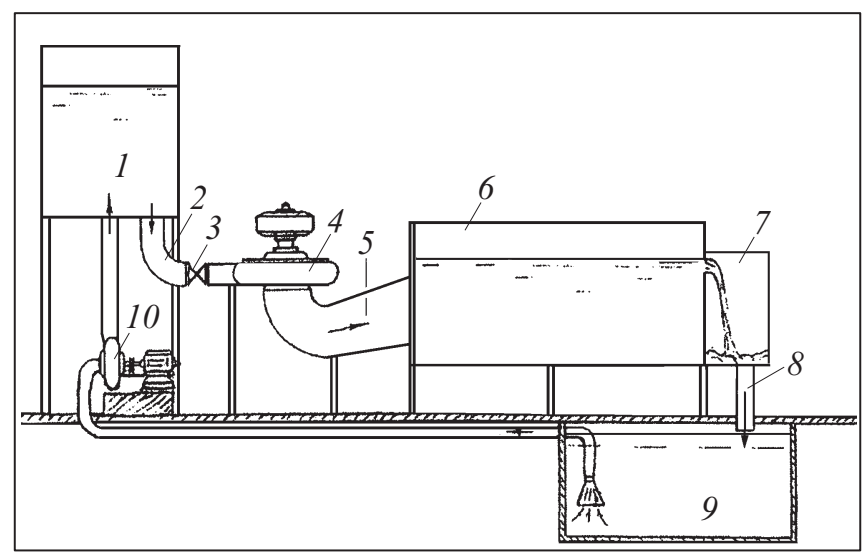

Рис. 1. Схема стенда гидротурбины.

мощности турбины). Однако в некоторых работах $[1,7,8]$ было установлено наличие апериодических всплесков, „ударов“ вследствие нерегулярной и нестабильной формы вихревого жгута в режимах, близких к оптимальному (70-80\% от номинальной мощности). В работах $[9,10]$ на модельном стенде с рабочим участком, имитирующим конический участок отсасывающей трубы гидротурбины, было обнаружено явление перезамыкания прецессирующего вихревого жгута с последующим формированием и отрывом вихревого кольца. Процесс перезамыкания является случайным, что дало основу для формулирования сценария возникновения апериодических „ударов“, обусловленных прохождением вихревых колец вблизи стенки [11].

О систематических экспериментальных исследованиях явления перезамыкания вихря в реальных гидротурбинах в настоящий момент неизвестно. Это и являлось основной мотивацией для проведения настоящей работы, в которой исследование выполнено на гидродинамическом стенде с радиально-осевой турбиной, являющийся среднемасштабной копией реального гидроагрегата.

Модельная гидротурбина с радиально-осевым колесом установлена на энергетическом стенде лаборатории гидравлики и гидромашин в Саяно-Шушенском филиале СФУ (рис. 1). Максимальный напор воды на стенде составляет $3.5 \mathrm{~m}$, диаметр рабочего колеса турбины $D=0.3 \mathrm{~m}$.

Письма в ЖТФ, 2017, том 43, вып. 21 
Гидроагрегатный блок включает следующие элементы: 1 - напорный бак, выполняющий функции верхнего бьефа, 2 - турбинный водовод диаметром $400 \mathrm{~mm}$ с задвижкой, снабженной электроприводом 3. Вода из водовода 2 поступает в спиральную камеру 4 , а затем через направляющий аппарат к рабочему колесу и далее, пройдя отсасывающую трубу 5 , в нижний бьеф 6 , представляющий собой остекленный лоток шириной $1.52 \mathrm{~m}$. После лотка вода сливается в сборный бак 7 и далее трубой 8 отводится в бассейн 9. Из бассейна 9 вода насосом 10 перекачивается обратно в напорный бак. Таким образом, обеспечивается непрерывная циркуляция воды в контуре.

Фиксация пульсаций давления на стенде производилась пьезоэлектрическими датчиками давления типа 014MT, предназначенными для преобразования быстропеременного и импульсного давления в электрический сигнал. Всего на стенде установлено пять датчиков давления: два в диффузоре, два в спиральной камере и один на выходе из отсасывающей трубы. Для усиления сигнала использовался внешний модуль LE-41, который является четырехканальным усилителем заряда. Для введения сигналов датчиков на ПК был использован АЦП Е14-140. Помимо пульсаций давления в работе измерялись напор, расход воды, частота вращения рабочего колеса, мощность, вырабатываемая турбиной. Диффузор отсасывающей трубы выполнен из оргстекла, что позволяет проводить оптическую диагностику потока и наблюдать за изменениями структуры течения.

Варьирование режимов работы на стенде осуществляется при помощи изменения напора и величины открытия направляющего аппарата. В ходе работы были проведены измерения пульсаций давления и визуализация структуры течения в широком диапазоне режимов работы гидроагрегата.

На рис. 2, $a$ показана визуализация вихревой структуры течения в режиме с открытием направляющего аппарата $5 / 15$ (напор $3.5 \mathrm{~m}$, расход воды $0.098 \mathrm{~m}^{3} / \mathrm{s}$, частота вращения рабочего колеса $8 \mathrm{~Hz}$ ), что соответствует примерно 64\% от максимальной мощности турбины. Как видно, в этом режиме формируется ярко выраженный концентрированный прецессирующий вихрь. Его прецессия носит регулярный характер, с частотой $2.5 \mathrm{~Hz}$. В этом режиме среднеквадратичное отклонение пульсаций давления (рис. 3,a) в диффузоре отсасывающей трубы достигает максимальной величины для данной турбины.

$3^{*}$ Письма в ЖТФ, 2017, том 43, вып. 21 

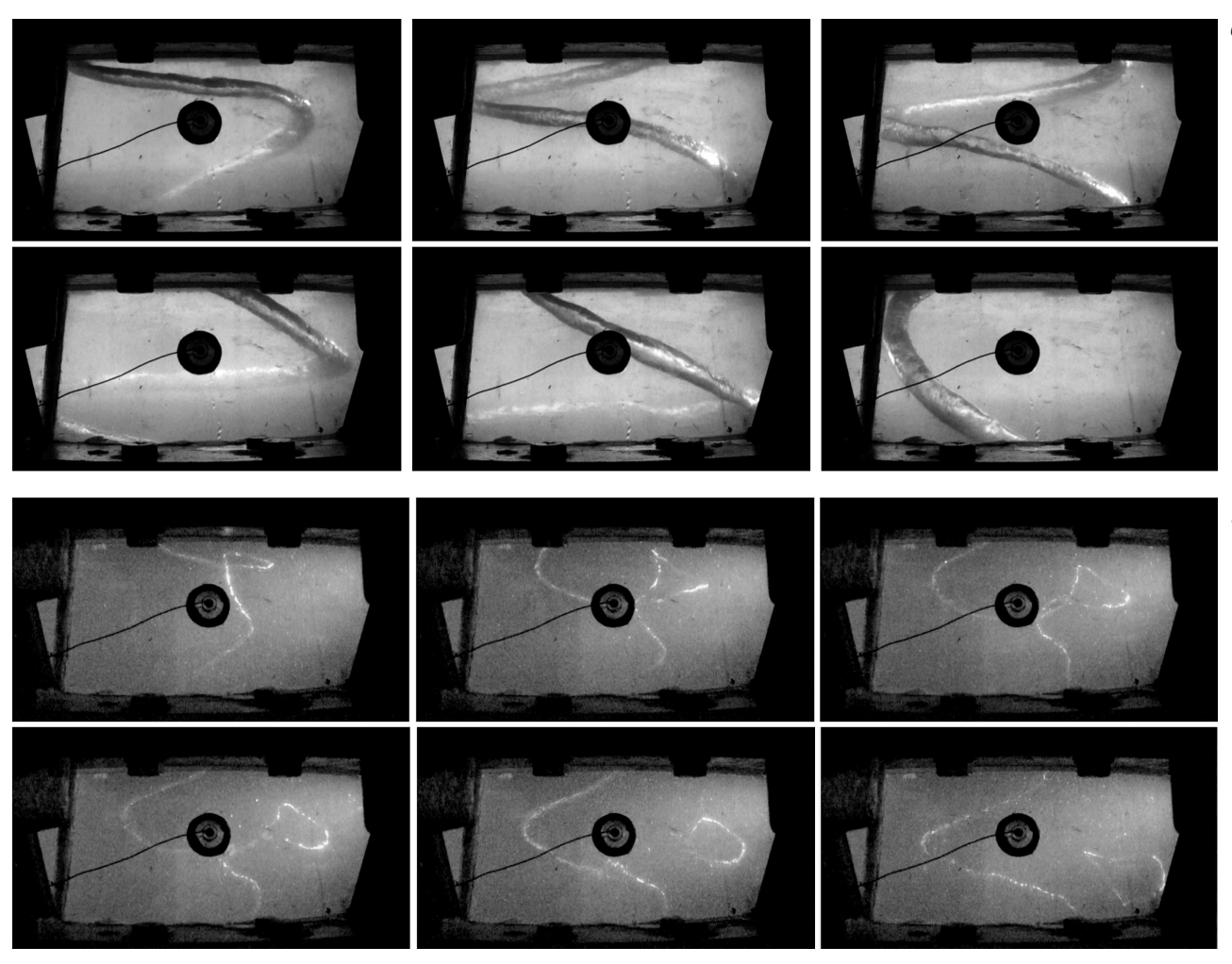

Рис. 2. Вихревая структура потока за рабочим колесом. $a$ - открытие $5 / 15, b-$ открытие $7 / 15$ 

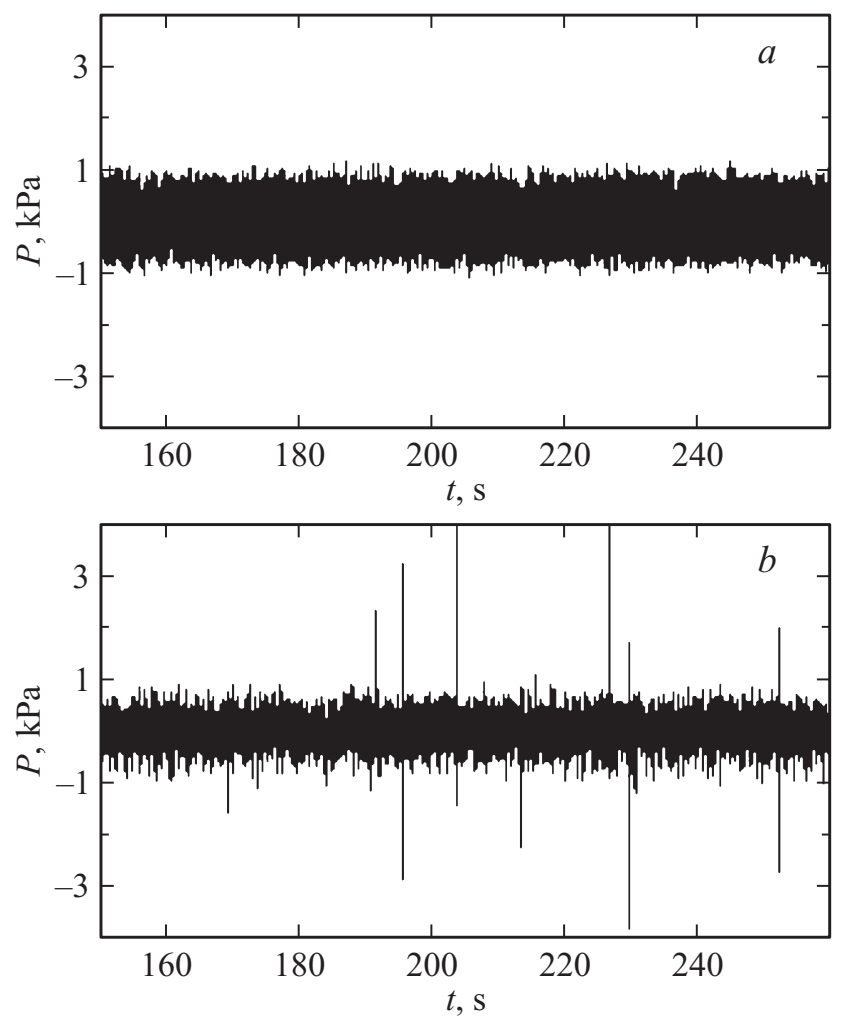

Рис. 3. Сигнал пульсаций давления в диффузоре отсасывающей трубы в зависимости от времени. $a$ - открытие 5/15, $b$ - открытие 7/15.

Визуализация вихревой структуры течения за рабочим колесом турбины позволила обнаружить перезамыкание вихря при открытии направляющего аппарата 7/15 (напор $3.5 \mathrm{~m}$, расход $0.114 \mathrm{~m}^{3} / \mathrm{s}$, частота вращения рабочего колеса $8 \mathrm{~Hz}$ ), что соответствует примерно $82 \%$ от максимальной мощности. На рис. $2, b$ показана динамика перезамыкания вихревого жгута с образованием вихревых колец. Как видно из этого рисунка, в данном режиме концентрированный вихрь в турбине является очень протяженным и при совершении прецессирующего движения

Письма в ЖТФ, 2017, том 43, вып. 21 
происходит его искажение с образованием петли с последующим отрывом вихревого кольца.

На рис. 3, $b$ показана зависимость статического давления от времени с одного из датчиков в диффузоре отсасывающей трубы. Хорошо видны нерегулярные всплески давления, которые по величине примерно в 3-4 раза превосходят общий уровень сигнала в этом режиме. Для сравнения на рис. 3, $a$ приведены пульсации давления в режиме с открытием 5/15, для которого прецессирующий жгут совершает регулярное периодическое вращение без перезамыкания. Как видно, никаких всплесков давления в данном режиме не наблюдается. Визуальные наблюдения позволили определить, что образование вихревых колец происходит достаточно регулярно с частотой примерно $0.45 \mathrm{~Hz}$, что соответствует 0.18 от частоты прецессии и 0.05 от оборотной. Однако из рис. $3, b$ видно, что всплески пульсаций давления нерегулярны и происходят гораздо реже. Синхронизация видеозаписи и сигнала датчика давления показала, что всплеск пульсаций давления наблюдается только тогда, когда вихревое кольцо либо попадает непосредственно в датчик, либо проходит очень близко с ним. И этот процесс имеет случайный характер. Аналогичное поведение было отмечено в работах $[8,9]$. Анализ сигнала давления с датчика, расположенного на противоположной стенке диффузора отсасывающей трубы, показал, что на нем также видны нерегулярные всплески. Они полностью рассинхронизированы со всплесками давления на первом датчике. Однако частота появления всплесков давления за одинаковый промежуток времени (25 min) для обоих датчиков примерно одинакова и составляет около $0.023 \mathrm{~Hz}$. Исходя из этого можно предположить, что вихревое кольцо воздействует на стенку отсасывающей трубы локально.

Таким образом, в работе на гидравлическом стенде с радиальноосевым колесом и конструкцией, максимально приближенной к реальным гидроагрегатам, впервые экспериментально зафиксированы апериодические всплески давления, связанные с перезамыканием вихря, образованием вихревых колец и их прохождением вблизи стенки. Это свидетельствует о том, что подобные явления могут иметь место в проточном тракте натурных гидротурбин. Поэтому перезамыкание вихря и образование вихревых колец в гидротурбинах представляют очень большой интерес для фундаментальной и прикладной науки и требуют дальнейшего изучения.

Письма в ЖТФ, 2017, том 43, вып. 21 
Работа выполнена при финансовой поддержке Российского фонда фундаментальных исследований, Правительства Красноярского края, Красноярского краевого фонда поддержки научной и научно-технической деятельности в рамках научного проекта № 16-41-243081 р_мол_а.

\section{Список литературы}

[1] Dorfler P., Sick M., Coutu A. Flow-induced pulsation and vibration in hydroelectric machinery. London: Springer-Verlag, 2013. 242 p.

[2] Minakov A.V., Sentyabov A.V., Platonov D.V., Dekterev A.A., Zakharov A.V. // Computer fluids. 2015. V. 111. P. 197-205.

[3] Platonov D., Minakov A., Dekterev D., Sentyabov A., Dekterev A. // J. Phys.: Conf. Ser. 2016. V. 754. P. 062007.

[4] Minakov A.V., Platonov D.V., Dekterev A.A., Sentyabov A.V., Pylev I.M., Zakharov A.V. // Power Techn. Eng. 2015. V. 49. Iss. 2. P. 90-97.

[5] Винокуров А.П., Шторк С.И., Алексеенко С.В. // Письма в ЖТФ. 2015. T. 41. B. 17. C. $61-67$.

[6] Скрипкин С.Г., Куйбин П.А., Шторк С.И. // Письма в ЖТФ. 2015. Т. 41. B. 13 . C. $48-55$.

[7] Nishi M., Liu S. // Int. J. Fluid Mach. Syst. 2013. V. 6. N 1. P. 33-48.

[8] Nicolet C., Zobeiri A., Maruzewski P., Avellan F. // Int. J. Fluid Mach. Syst. 2011. V. 4. N 1. P. 179-190.

[9] Скрипкин С.Г., Цой М.А., Шторк С.И., Куйбин П.А. // Вестн. Новосиб. гос. ун-та. Сер. Физика. 2016. Т. 11. № 4. С. 25-32.

[10] Алексеенко С.В., Куйбин П.А., Шторк С.И., Скрипкин С.Г., Цой М.А. // Письма в ЖЭТФ. 2016. Т. 103. В. 7. С. 516-521.

[11] Alekseenko S.V., Kuibin P.A., Shtork S.I., Skripkin S.G., Sonin V.I., Tsoy M.A., Ustimenko A.S. // IOP Conf. Ser:: Earth and Environmental Sci. 2016. V. 49. P 082025 (1-8). 